\title{
Aniline and Esters-An Ultrasonic Study
}

\author{
Sathi Reddy.K, ${ }^{1}$ Shanmukhi Jyothi.D, ${ }^{2}$ Linga Reddy.D ${ }^{3}$ \\ ${ }^{I}$ Department of Physics, College of Natural Science, Arba Minch University, Ethopia. \\ ${ }^{2}$ Dept of Physics, Sardar Patel College, Secunderabad-500 025 (A.P), India. \\ ${ }^{3}$ Dept of Physics, UCS, Osmania University, Hyderabad -500007, (A.P), India
}

\begin{abstract}
Ultrasonic velocity (v), Density ( $\rho)$, Refractive index ( $n)$ for binary mixtures of Aniline with Methyl Acetate, Ethyl Acetate and Amyl Acetate have been measured at room temperature of about $300.15 \mathrm{~K}$ over entire volume component percentage range. The Ultrasonic velocity $(v)$ is measured using Ultrasonic Pulse Echo Overlap (PEO) technique at a frequency of $2 \mathrm{MHz}$. The density measurements have been carried out by using $10 \mathrm{ml}$ specific gravity bottle. Refractive index (n) measurements have been carried out by using Abbe Refractometer. Adiabatic Compressibility $\left(\beta_{s)}\right.$ and dielectric constant $(\epsilon)$ were computed using measured data of density, ultrasonic velocity and refractive index.
\end{abstract}

Key Words: Ultrasonic Velocity, density, refractive index, adiabatic compressibility, dielectric constant.

\section{Introduction}

Ultrasonic measurement finds extensive applications [1-2] in characterizing the various aspects of the physico-chemical behavior of liquid mixtures such as molecular interaction and association. Molecular association and complex formation in liquid mixtures through ultrasonic velocity measurements have been studied by Reddy, Naidu [3-4].

Ultrasonic velocity of a liquid is related to binding forces between atoms and molecules. Ultrasonic velocities have been adequately employed in understanding the molecular interactions in pure liquids and liquid mixtures as it plays a major role. The sound velocity in liquid mixtures is known to be a quantity, which depends on concentration in a variety of manners according to the nature of each component liquid. Accurate measurements of ultrasonic velocity deliver the information about physical and chemical behaviour of solutions and liquid mixtures such as molecular association and dissociation. Data of ultrasonic velocity (v), density $(\rho)$ are useful in evaluating some useful thermo dynamic properties like adiabatic compressibility $\left(\beta_{\mathrm{s}}\right)$, which can be utilized as a qualitative guide to predict the extent of complex formation in binary liquid mixtures. There are different theories available to predict the properties of pure liquids. The parameters obtained in such a study are used in turn to derive an insight into the molecular interactions present in such systems. Ultrasonic velocity has been subject of active interest during the recent years [5-7]. Nomoto and co-researchers made successful attempts to evaluate the sound velocity in binary mixtures. In the present communication we focus on the ultrasonic behavior of liquid mixtures at $300.15 \mathrm{~K}$ temperature with Aniline as the base and few Esters like Ethyl Acetate, Methyl Acetate and Amyl Acetate as mixtures.

\section{Experimental}

Ultrasonic technique has been widely used for different types of investigation [8].In Pulse Echo Overlap method a short sinusoidal electrical wave activates the Ultrasonic transducer. The transducer then produces sound wave trains into the liquid inside the cell. This cell is made up of stainless steel which avoids any chemical reactions between the chemicals and the cell.

The Ultrasonic velocity was measured with the help of microprocessor based Ultrasonic Pulse Echo Overlap (PEO) technique supplied by Roop Telesonic, Bombay at $2 \mathrm{MHz}$ frequency. The internal circuit of (ULTRASONIX 4400M) is designed with full solid state version. Further outstanding stability and reliability of operation is ensured by dynamic use of integrated circuit and PCB mounted gold switches. It has special memory features which enable one to enter testing procedures like angle and type of transducer for permanent storage and direct digital read out of Ultrasonic velocity up to an accuracy of $\pm 1 \mathrm{~m} / \mathrm{s}$. The Pulse Echo Overlap (PEO) method is very versatile and highly accurate technique for measuring the velocity of the ultrasonic waves in materials of liquids and solids structures. A highly absolute accuracy is obtained from this system, since the method is capable of accurately measuring from any cycle of one echo to the corresponding cycle of the next echo. The PEO method is able to handle diffraction (beam spreading) and phase correction properly, so that absolute accuracy of the PEO method may exceed the accuracy of most of the other methods. However, precision of some other methods is better than PEO method. Ravinder Reddy, B and Linga Reddy, D (1999) improved and used this technique to measure the velocities and attenuations in liquids and solids. 
The PEO method may operate either with transducer bonded to the specimen or directly with RF bursts. On the negative side, because of transducer effects, the leading cycles of successive echoes are attenuated and trailing cycles are burst up, so that great care has to be taken to obtain proper cycle for cycle match. The phase correction and identification of cycles are to be taken properly which is mentioned in Pulse Superposition technique.

The densities of all the mixtures have been determined with $10 \mathrm{ml}$. specific gravity bottle and mass $(\mathrm{m})$ of a given volume of the liquid is determined by using a single pan opto-electrical balance. The results of the densities are accurate to $\pm 0.5 \%$. The refractive index (n) of the mixture has been determined using an Abbe Refractometer (Model SER no.86002, Advanced Research Instruments Company, New Delhi) with an accuracy of $\pm 0.2 \%$.

\section{Results And Discussion}

Ultrasonic velocity decrease in Aniline-Methyl Acetate, Aniline-Ethyl Acetate, Aniline-Amyl Acetate (Table-1).Ultrasonic velocity is larger in Aniline-Amyl Acetate the reason being that Amyl Acetate is more alcoholic. Aniline is a basic component and possesses less number of $\mathrm{H}^{+}$ions which causes for freer movement of Ultrasonic waves through the medium. Therefore Ultrasonic velocity increases with respect to the increase in Aniline concentration. The density values decrease with respect to the increase in Ester concentration in all the systems. The density values are lesser in Aniline-Amyl Acetate system and larger in Aniline-Methyl Acetate system. The order of densities is Amyl Acetate < Ethyl Acetate < Methyl Acetate.

The primary effect of dissolving an electrolyte is to lower the compressibility of the solvent. This lowering is attributed to the influence of the electrostatic field of the ion on the surrounding solvent molecules and thus the total internal pressure increases and the solution becomes harder to compress.

The hydrogen bonding in Esters makes Esters as solvents. Esters are miscible in Aniline because of the accepting nature of $\mathrm{H}^{+}$bonds. A correlation of ultrasonic velocity (v) with dielectric constant indicates that there is a decrease in dielectric constant with increase in ultrasonic velocity (v). The more polar is the medium larger is the ultrasonic velocity and hence dielectric constant is larger.

The Adiabatic compressibility $\left(\beta_{\mathrm{s}}\right)$ is calculated using the formula

$$
\beta_{\mathrm{s}}=1 / \mathrm{v}^{2} \rho
$$

The Adiabatic compressibility $\left(\beta_{\mathrm{s}}\right)$ depends on the interaction between the molecules since work has to be done against the repulsive forces between the molecules during the compression of the liquids. The decrease in adiabatic compressibility may be due to the fact that in solution the ions are surrounded by a layer of solvent molecules firmly bound to and oriented towards the ions.

The orientation of the solvent molecules around the ions may be due to the influence of the electro static field of the ions and results in an internal pressure and in a lowering of adiabatic compressibility of the solution.ie. solution becomes much harder to compress which is in tune with Sathi Reddy et al. Thus the adiabatic compressibility lowering is caused by an electrolyte at a particular temperature and the concentration is dependent on the ionic strength of the solution. Similar results have been obtained for alkali halides [9-12] mixtures.

The refractive index (n) decrease with increase in Ester concentration and these are reported in tables 1, 2, 3. which shows that Amyl Acetate>Ethyl Acetate>Methyl Acetate.Fig.2 show variation of density of alcohols and is in good agreement with the theory postulated by Rajagopalan [13-16].

The macro dielectric constant $(\mathrm{D}=\mathrm{C})$ is calculated using the formula which is derived from Maxwell's theory of Electromagnetism

$$
\mathrm{D}=\sqrt{\mathrm{n}}
$$

\section{Conclusions}

Thermo dynamical and optical studies are carried out apart from ultrasonic studies on Methyl Acetate, Ethyl Acetate, and Amyl Acetate with Aniline over entire volume component percentage range. It is found that Ultrasonic velocity increases with increase in Ester concentration. Refractive index decreases with increase in concentration of Esters. 
Table (1) Ultrasonic velocity (v), density ( $\rho$ ), adiabatic compressibility ( $\beta \mathrm{s})$, Refractive index (n), Macro dielectric constant (C) of Binary mixture of Aniline in Methyl Acetate at $300.15 \mathrm{~K}$

\begin{tabular}{|c|c|c|c|c|c|c|}
\hline \multicolumn{2}{|c|}{$\begin{array}{l}\text { Volume Component } \\
\text { Percentage }\end{array}$} & \multirow{2}{*}{$\begin{array}{l}\text { Ultrasonic } \\
\text { Velocity } \\
(\mathrm{v}) \\
\mathrm{m} / \mathrm{s}\end{array}$} & \multirow{2}{*}{$\begin{array}{c}\text { Density } \\
(\rho) \\
10^{-3} \mathrm{~kg} / \mathrm{m}^{3}\end{array}$} & \multirow{2}{*}{$\begin{array}{c}\text { Adiabatic } \\
\text { compressibility } \\
\left(\beta_{\mathrm{s}}\right) \\
10^{-10} \mathrm{~m}^{2} \mathrm{~N}^{-1}\end{array}$} & \multirow{2}{*}{$\begin{array}{l}\text { Refractive } \\
\text { index } \\
\text { (n) }\end{array}$} & \multirow{2}{*}{$\begin{array}{l}\text { Macro } \\
\text { dielectric } \\
\text { constant } \\
(\mathcal{C})\end{array}$} \\
\hline Aniline & $\begin{array}{l}\text { Methyl } \\
\text { Acetate }\end{array}$ & & & & & \\
\hline 90 & 10 & 1502 & 1.0182 & 4.354 & 1.515 & 1.2308 \\
\hline 80 & 20 & 1439 & 1.0068 & 4.799 & 1.509 & 1.2284 \\
\hline 70 & 30 & 1407 & 1.0053 & 5.026 & 1.503 & 1.2259 \\
\hline 60 & 40 & 1370 & 0.9962 & 5.335 & 1.486 & 1.219 \\
\hline 50 & 50 & 1327 & 0.9820 & 5.765 & 1.483 & 1.2177 \\
\hline 40 & 60 & 1285 & 0.9784 & 6.171 & 1.468 & 1.219 \\
\hline 30 & 70 & 1240 & 0.9718 & 6.692 & 1.450 & 1.2041 \\
\hline 20 & 80 & 1200 & 0.9521 & 7.235 & 1.414 & 1.1891 \\
\hline 10 & 90 & 1150 & 0.9450 & 7.935 & 1.365 & 1.1811 \\
\hline
\end{tabular}

Table (2) Ultrasonic velocity (v), density ( $\rho$ ), adiabatic compressibility ( $\beta s)$, Refractive index (n), Macro dielectric constant (C) of Binary mixture of Aniline in Ethyl Acetate at $300.15 \mathrm{~K}$

\begin{tabular}{|c|c|c|c|c|c|c|}
\hline \multicolumn{2}{|c|}{ Volume Component Percentage } & \multirow{2}{*}{$\begin{array}{c}\text { Ultrasonic } \\
\text { Velocity } \\
\text { (v) } \\
\mathrm{m} / \mathrm{s}\end{array}$} & \multirow{2}{*}{$\begin{array}{c}\text { Density } \\
(\rho) \\
10^{-} \\
{ }^{3} \mathrm{~kg} / \mathrm{m}^{3} \\
\end{array}$} & \multirow{2}{*}{$\begin{array}{c}\text { Adiabatic } \\
\text { compressibility } \\
\left(\beta_{\mathrm{s}}\right) \\
10^{-10} \mathrm{~m}^{2} \mathrm{~N}^{-1}\end{array}$} & \multirow{2}{*}{$\begin{array}{l}\text { Refractive } \\
\text { index } \\
\text { (n) }\end{array}$} & \multirow{2}{*}{$\begin{array}{c}\text { Macro } \\
\text { dielectric } \\
\text { constant } \\
(\epsilon)\end{array}$} \\
\hline Aniline & Ethyl Acetate & & & & & \\
\hline 90 & 10 & 1502 & 1.0095 & 4.391 & 1.576 & 1.2503 \\
\hline 80 & 20 & 1457 & 1.0017 & 4.704 & 1.545 & 1.2429 \\
\hline 70 & 30 & 1412 & 0.9905 & 5.064 & 1.543 & 1.2421 \\
\hline 60 & 40 & 1373 & 0.9879 & 5.371 & 1.514 & 1.2325 \\
\hline 50 & 50 & 1329 & 0.9853 & 5.748 & 1.501 & 1.228 \\
\hline 40 & 60 & 1288 & 0.9717 & 6.206 & 1.486 & 1.2108 \\
\hline 30 & 70 & 1244 & 0.9489 & 6.812 & 1.478 & 1.2105 \\
\hline 20 & 80 & 1203 & 0.9289 & 7.441 & 1.464 & 1.184 \\
\hline 10 & 90 & 1153 & 0.9243 & 8.143 & 1.395 & 1.171 \\
\hline
\end{tabular}

Table (3) Ultrasonic velocity (v), density ( $\rho$ ), adiabatic compressibility ( $\beta$ s), Refractive index (n), Macro dielectric constant ( () ) of Binary mixture of Aniline in Amyl Acetate at $300.15 \mathrm{~K}$

\begin{tabular}{|c|c|c|c|c|c|c|}
\hline \multicolumn{2}{|c|}{ Volume Component Percentage } & \multirow{2}{*}{$\begin{array}{l}\text { Ultrasonic } \\
\text { Velocity } \\
\text { (v) } \\
\mathrm{m} / \mathrm{s}\end{array}$} & \multirow{2}{*}{$\begin{array}{c}\text { Density } \\
(\rho) \\
10^{-} \\
{ }^{3} \mathrm{~kg} / \mathrm{m}^{3}\end{array}$} & \multirow{2}{*}{$\begin{array}{c}\text { Adiabatic } \\
\text { compressibility } \\
\left(\beta_{\mathrm{s}}\right) \\
10^{-10} \mathrm{~m}^{2} \mathrm{~N}^{-1}\end{array}$} & \multirow{2}{*}{$\begin{array}{l}\text { Refractive } \\
\text { index } \\
\text { (n) }\end{array}$} & \multirow{2}{*}{$\begin{array}{c}\text { Macro } \\
\text { dielectric } \\
\text { constant } \\
(€) \\
\end{array}$} \\
\hline Aniline & Amyl Acetate & & & & & \\
\hline 90 & 10 & 1504 & 1.0142 & & 1.573 & 1.2541 \\
\hline 80 & 20 & 1460 & 1.0097 & $\begin{array}{l}4.359 \\
4.610\end{array}$ & 1.554 & 1.2465 \\
\hline 70 & 30 & 1417 & 0.9781 & $\begin{array}{l}4.049 \\
5.095\end{array}$ & 1.548 & 1.2441 \\
\hline 60 & 40 & 1390 & 0.9641 & $\begin{array}{l}5.095 \\
5.368\end{array}$ & 1.520 & 1.2328 \\
\hline 50 & 50 & 1348 & 0.9520 & $\begin{array}{l}5.500 \\
5.782\end{array}$ & 1.509 & 1.2284 \\
\hline 40 & 60 & 1301 & 0.9423 & $\begin{array}{l}5.182 \\
6274\end{array}$ & 1.497 & 1.2235 \\
\hline 30 & 70 & 1278 & 0.9208 & $\begin{array}{l}0.214 \\
6.346\end{array}$ & 1.483 & 1.2177 \\
\hline 20 & 80 & 1240 & 0.9023 & $\begin{array}{l}0.340 \\
7.164\end{array}$ & 1.462 & 1.191 \\
\hline 10 & 90 & 1203 & 0.8906 & $\begin{array}{l}.1 .104 \\
7.761\end{array}$ & 1.414 & 1.1891 \\
\hline
\end{tabular}




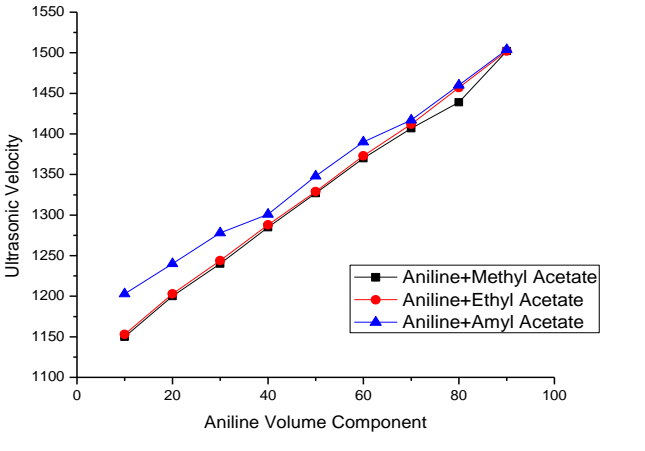

Figure 1. Aniline Volume Component vs Ultrasonic Velocity

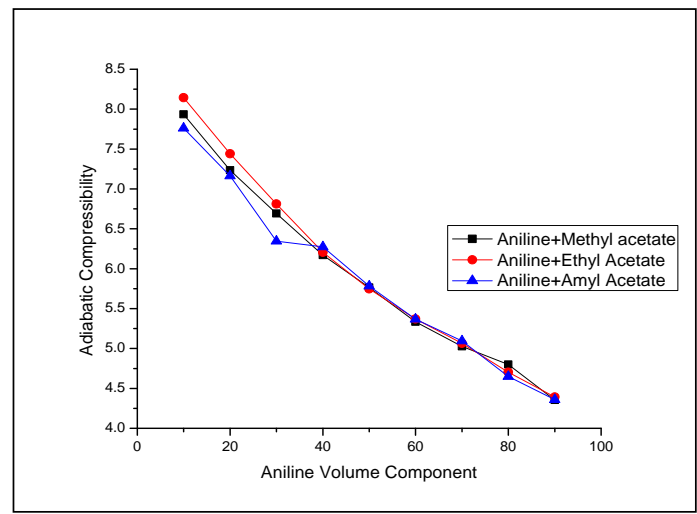

Figure 3. Aniline Volume Component vs Adiabatic Compressibility Index

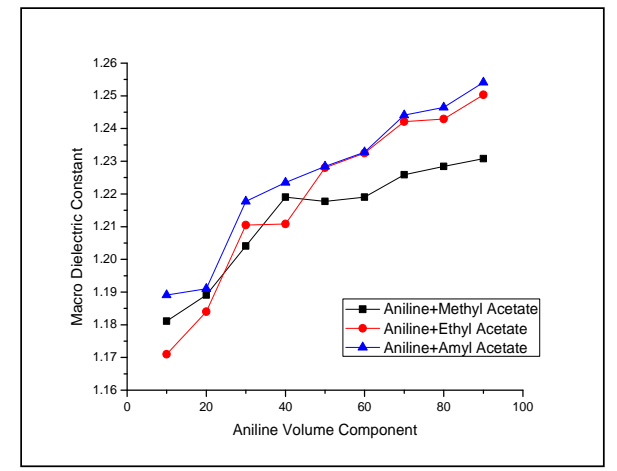

Figure 5. Aniline Volume Component vs Macro Dielectric Constant

\section{References}

[1] H.Eyringand Hirschfelder,J.O.,J.Phy.chem 41 (1937),249.

[2] R.J.Fort and W.R. Moore,Trans, Faraday Society 61 (1979),687.

[3] K.Subramanyam Reddy and P.R.Naidu,Aust.J.Chem 32 (1979),687

[4] K.Sathi reddy and d.Linga Reddy, Journal of Ultrasonics.(2007)

[5] B.Ravinder Reddy and D.Linga Reddy, Ind.J.Pure and Appl.Phy, 37(1999)56.

[6] N.Jaya Kumar, Karunanidhi and V.Appan, Ind.J.Pure and Appl. Phy 34(1999)76.

[7] S.V.Ranganayakulu, C.Sreenivas Reddy and D.Linga Reddy, J. AcousticalS ociety of India 31(2003)295.

[8] H.Eyring,J.F. Kincaid, J.Chem. Phy 6 (1938) 67.

[9] V.K.Syal,Kumari,U.Chauhan,S.Chauhan,M.S.Sud,S.P.Singh,Indian J.Pure and Appl. Phy (1992).

[10] S.Rajagopalan, Acoustica, 66(1988)63.

[11] K.S.Reddy, P.R. Naidu, J. Chem. Liq.15 (1985) 147.

[12] C.Bachem, Z. Physik 101 (1936) 565.

[13] G. V. Reddy, R.P. Singh, Acustica 23 (1970) 31.

[14] S.C.Bhatt, R.S.Rawat and B.S. Semwal,J.Acoust..Soc.India, 27(1999)297.

[15] J.Prakash and B.Rai, Acoustica, 64(1987)226

[16] O.Nomoto et al, J.Phy.Soc.Japan Vol.8, 4 July-August 1953.

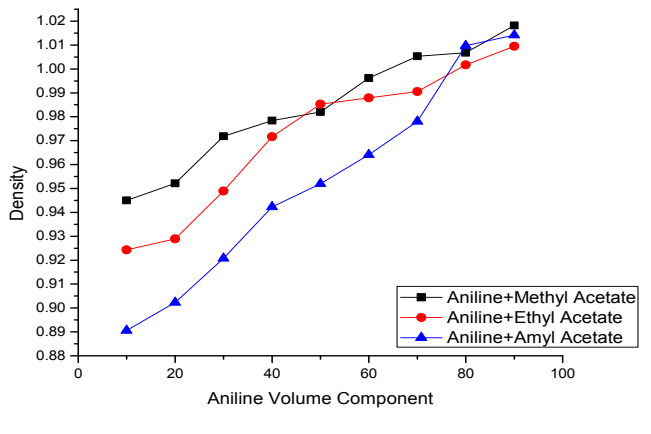

Figure 2. Aniline Volume Component vs Density

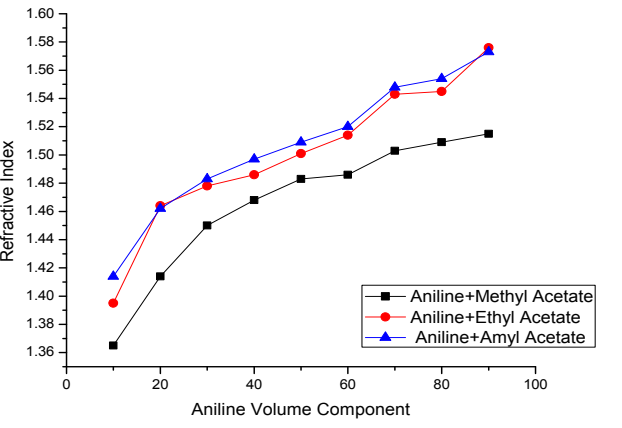

Figure 4. Aniline Volume Component vs Refractive 